\title{
REHACIENDO LA IMAGEN DE LA RELACIÓN CRISTIANO-JUDIA: UNA EVALUACIÓN DE LAS PERSPECTIVAS CONTEMPORÁNEAS
}

John Panlikowski

$\mathrm{E}$ I diảlogo contemporáneo con los judíos y el judaismo ha comenzado a demostrar un impacto en el entendimiento del Nuevo Testamento y del cristianismo primitivo tanto en círculos cristianos como judios. Somos testigos de una revolución genuina en el estudio del Nuevo Testamento cristiano $y$, a la vez, en el estudio paralelo del judá́smo durante el mismo periodo. Dentro del estudio bíblico cristiano, estamos experimentando un final rápido del dominio del temprano Religiongerchichte (historia de la religión), que enfatizó la casi totalidad del pasado helenístico del cristianismo paulista tanto como su tiempo subsiguiente, manifestación de alguna forma modificada en los escritos de Rudolf Bultmann y algunos de sus discípulos, como Ernst Kasemann y Helmut Koester. Estos acercamientos exegéticos al Nuevo Testamento gastaron seriamente los lazos concretos y la dependencia de Jesús al judaísmo bíblico y al Segundo Templo. Este hecho, en su momento, produjo una interpretación excesivamente universalista del mensaje de Jesús que abrigó las semillas del antijudaísmo teológico.

Hubo un número de principales escritos bíblicos, algunos con una continua influencia transcontinental, que contribuyỏ a la de-judaización 
de la fe cristiana, Uno de los más prominentes ha sido Gerhard Kittel, el editor original del ampliamente usado Theological Dictionary of The Nenz Testament.' Kittel visualizó el judaísmo postbíblico como, en gran parte, una comunidad en dispersión: el «qudaísmo auténtico yace en el símbolo del extraño que vaga sin descanso y sin hogar por la faz de la tierran, ${ }^{2} Y$ el destacado exegeta Martin Noth, cuya History of Israelllegó a ser una referencia estándar para los alumnos y profesores por igual, describió a Israel como una estricta «comunidad religiosa» que moria lentamente, muerte agonizante en el siglo I d.C. Para Noth, la historia judia alcanzó su culminación con la llegada de Jesús. Sus palabras son concisas y directas en este aspecto; đJesús mismo [...] no siguió formando parte de la historia de Israel. En él la historia de Israel ha llegado, más bien, a su final real. Lo que sí perteneció a la historia de Israel fue el proceso de su expulsión y condenación por la comunidad religiosa de Jerusalén... Después en adelante la historia de Istael se movió rápidamente hasta el finals, ${ }^{3}$

Un tercer ejemplo es Rudolf Bultmann, quien ejerció una influencia decisiva sobre la interpretación bíblica cristiana por décadas, A diferencia de Kittel, quien fue retirado de su puesto de enseñanza en Tubingen en 1945 debido a sus explícitas simpatías pro nazis, la exégesis de Bultumann no llegó hasta la política; pero, hablando teológicamenté, su comprensión del Acontecimiento de Cristo también dejó a los judíos y al judaísmo con poco o ningún significado después de la venida de Jesús. En su Tbeology of The Nen Testament, llegó a una visión similar a la de Martin Noth. Para Bultmann, no puede hablarse de un pueblo judío que exista con la fusión del cristianismo. Para él, la ley judía, ritual y piadosa, retiró a Dios a un reino distante. Por el contrario, la presencia continua de Jesús en oración y adoración permitió que cada cristiano, individualmente, se acercara más a Dios. El entendimiento de Bultmann del judaísmo en los días de Jesús estaba basado en recursos 
totalmente inadecuados en términos del judaismo del Segundo Templo y la relación de Jesús hacia sus eniseñanzas y espiritu.

Esta tradición, profundamente establecida, de separar a Jesús del judaísmo ha continuado manifestándose en estudios biblicos más recientes. Eruditos como Norman Perin y John Dominic Crossan interpretaron frecuentemente las parábolas de Jesûs de tal forma que se les daba un tono antijudio. En esto, con especial incidencia, el trabajo de toda la vida de Clemens Thoma sobre las parábolas ha dado una contribución tan importante como la contraposición a la continua tendencia bultmanniana. La perspectiva bultmanniana/nothiana ha emergido en algunos de los teólogos dela liberación curyo trabajo está profundamente encaizado en la tradición bíblica. Los escritos de Gustavo Gutiérrez y Jon Sobrino nos ofrecen dos ejemplos importantes del continuo impacto de la sombra bultmanniana. Gutiérrez, por ejemplo, ha escrito que desde que «las infidelidades del pueblo Judio hicieron el Antiguo Pacto inválido, la Promesa fue encarnada en la proclamación del Nuevo Pacto, el cual fue esperado y sostenido por "el resto", tanto como en las promesas que prepararon y acompañaron su advenimientom. ${ }^{5} \mathrm{Y}$ Clark Williamson, en un estudio detallado de la Christology at The Roads de Jon Sobrino, ha concluido que ucada aspecto de su modelo anti-judaico se encuentra en la Christology at The Roads de Sobrino. Cada tema puede ser documentado en su textom."

En varias de las últimas décadas, hemos visto un dramático cambio desde la predominancia del entendimiento antijudaico del Nuevo Testarnento promocionado por los gustos de Kittel, Noth y Bultmann, Guiado por eruditos como W. D. Davies,' E. P. Sanders, Douglas Hare, Daniel Harrington, Robin Scroggs y, por supuesto, Clemens Thoma, la lista de esos que repudian lo que Arthur ]. Droge ha llamado el kcautiverio bultmannianom de la exégesis del Nuevo 'Testamento continúa créciendo. 
Unárea importante al respecta es el estudio paulino que ha probado ser tan influyente a lo largo de los siglos en definir la identidad propia del ctistiano comparado con el judaísmo. Ciertos eruditos judíos han intensificado la figura antijudaica de Pablo y han sostenido que mientras Jesús puede haber sido un disidente en términos de la tradición judía, Pablo permanece claramente atado a la comunidad de Israel. Pot otro lado, fue responsable de las diferencias entre iglesia y sinagoga. El obispo retirado Krister Stendahl comenzó el proceso de reconsideración con respecto a Pabla y el judaísmo hace varias décadas. E. P. Sanders, Peter Tomson, James D. G. Dunn, Daniel Harrington y Lloyd Gaston han seguido la guía de Stendahl. A ellos se les han unido varios últimos eruditos judíos, el más notable es Alan Segal.

Lo que está comenzando a surgir de este nuevo estudio paulino es la figura de Pablo, todavía muy judio, todavia bastante agradecido del Torah (puede haber también asumido su continua vigencia por los judíos cristianos), y todavia peleando hasta el final de su ministerio para balancear su comprensión de lo nuevo implicado en el Acontecimiento de Cristo con la continuidad del pacto judio, algo bastante aparente en los famosos capitulos 9-11 de Romanos, en los cuales el Varicano II construyó su comprensión revolucionaria de la relación de la Iglesia hacia el pueblo judía. Es también posible que algunos de los escritos paulinos, especialmente aquellos que han servido como la base del pensamiento cristológico último, podrian tener sus raices en el contacto personal de Pablo con el misticismo judío de su tiempo, aunque hubiera agregado su interpretación distintiva."

Nosotros también hemos visto, tanto en las declaraciones oficiales de la Iglesia y entre los eruditos del Nuevo Testamento, una apreciación creciente de Jesús echando taíces en el judaísmo progresivo de su tiempo. James Charlesworth y el cardenal Martini S. J., arzobispo retirado de Milán, 
son dos primeros ejemplos de esa nueva interpretación. El primero ha escrito que «sin un sentimiento sincero por el mundo Judio y una experiencia directa de este, uno no puede entender completamente el cristianismo. Jesús es completamente judio, los apóstoles son Judíos, y uno no puede dudar suarraigo a las tradiciones de sus antecesoresm. "Y el texto de las notas del Vaticano de 1985 acerca de las prédicas y enscrianza con respecto a los judíos y el judaísmo declara que ujesús fue y siempre permaneció judio... Jesús es completamente un hombre de su tiempo, y su ambiente - la Palestina judia, la del siglo primero-, las ansiedades y esperanza que el compartiay, ${ }^{10}$ En otras palabras, ambos estudios recientes, como la enserianza católica oficial, sostienen que cualquier retrato de jesús que lo separe del judaísmo de su tiernpo en la manera que lo hace Bultmann representa una presentación truncada y distorsionada de su mensaje y misión. Para Jesús, no habia «Antiguo Testamentom; habia solo sLas Escrituras» que él integró profundamente en una forma constructiva a su predicación.

Uno de los mejores resúmenes sobre dónde estamos hoy en têrminos de la relación de Jesús hacia el judaísmo de su tiempo, y las implicaciones que tiene para entender la relación iglesia-sinagoga, ha venido del erudito bíblico Robin Scroggs. Su punto de vista ha sido aprobado por el fallecido cardenal Joseph Bernardin de Chicago, un líder en promover la reconciliación judio-católica en sus propios escritos." Scroggs enfatiza los siguientes puntos:

- El movimiento que empezó por Jesús y continuó después de su muerte en Palestina puede ser descrito como un movimiento reformista dentro del judaismo.

- Hay poca evidencia durante este periodo de que los cristianos tuvieran identidad separada de los judíos. 
- El movimiento misionero paulista, como Pablo lo entendió, fue una misión judia que se centró en los gentiles como finalidad del llamado de Dios a sugente.

- Anterior al final de la guerra judía con los romanos en el año 70 de la era cristiana, no hay tal realidad como cristianisma.

- Los seguidores de Jesús no tenían un entendimiento propio de ellos mismos como religión en contrariedad con el judaísmo.

- Una identidad cristiana distintiva solo comenzó a surgir después de la guerra judio-romana.

- Las últimas partes del final del Nuevo Testamento muestran todas algunos signos de un movimiento que va a la separación, pero también, generalmente, conservan algún contacto con su matriz judía.

Mientras no todo erudito en el Nuevo Testamento puede suscribir cada y todo preciso punto hecho por Scroggs, el consenso está creciendo respecto de que la figura que él muestra es básicamente clara. Un cuadro así contradice claramente las figuras de la separación cristiano-judia sostenida por la mayoría de las personas en cada tradición de fe.

A medida que los eruditos bíblicos y teólogos han comenzado a sondear las implicaciones de esta nueva visión de Jesús como profundamente entrelazado con la comunidad judía de su tiempo, dos alcances iniciales han venido al frente en términos de entendimiento de su relación y la de la comunidad cristiana con el pueblo de Israel. Mientras aparecen diferentes matices dentro de cada alcance, a la vez que nos movemos de erudito a erudito, podemos caracterizar las dos tendencias como las perspectivas de un kúnico pacton y un "pacto doble» que pocos eruditos, como Rosemary Radford Ruether y Paul Knotter, han discutido por pactos múltiples. 
El primer alcance es generalmente llamado la teoria del pacto único. Sostiene que los judios y cristianos básicamente pertenecen a una tradición pactada que comenzó en el Sinai. En esta perspectiva, el Acontecimiento de Cristo representaba el momento decisivo en el que los gentiles fueron capaces de entrat completamente en una relación especial con Dios, relación dela que los judíos ya gozaban y en la cual continuaron. Algunos que sostienen este punto de vista mantienen que los rasgos decisivos del Acontecimiento de Cristo tienen aplicación universal, incluyendó a los judios. La declaración en la Biblia judia, retirada a fines del año 2001 por la Comisión Bíblica Pontificia del Vaticano, parece afirmar que, en el tiempo histórico, los judíos esperan al Mesías a través de su propio pacto. Na hay necesidad por parte de los judios de convertirse al cristianismo; pero cuando el Mesias judio finalmente llegue, él tendrá las características integras del mesianismo de Jesús. Por eso, el mesianismo de Jesús conserva implicaciones universales. Otros estudiosos en esta discusión continua se inclinan más a afirmar que la apropiación y reinterpretación de la tradición original crìstiana, pactada en y a través de Jesús, se aplica primariamente a lo no-judio.

La teoría del pacto doble, con la cual estoy a favor, comienza en el mismo punto que su contraparte: el único pacto, a saber, con afirmación firme de lazos continuos entre cristianos y judios. Sin embargo, prefiere subrayar los distintivos de las dos tradiciones y comunidades, particularmente en términos de sus experiencias después de la separación final de la iglesia y la sinagoga. Los cristianos asociados con esta perspectiva insisten en mantener el punto de vista de que a través del ministerio, enseñanzas y persona de Jesús surgió una visión de Dios que fue distintivamente nueva en términos de sus rasgos centrales. Aunque puede haber existido un fundamento importante para este surgimiento en el Segundo Templo o judaísmo medio, lo que vino 
para ser entendido tomando en cuenta la relación divino-humana como un tesultado de Jesús, tiene que ser considerado como un salto cuántico.

Es muy posible que las discusiones referentes a la mejor forma de reformular una teología del pacto cristiano continuarán formalmente en un futuro visible. El cardenal Walter Kasper, Presidente de la Comisión de la Santa Sede para las Relaciones Religiosas con los Judios, ha intentado tal reformulación en una mención a los encuentros realizados durante el Diálogo Judío Internacional (Nueva Cork, mayo de 2001) y el Concilio Internacional de Cristianos y Judios (Montevideo, julio de 2001). ${ }^{2}$ Muchos eruditos se sienten ahora insatisfechos con las opciones de los pactos único y doble. Esta insatisfacción proviene de la nueva investigación en la naturaleza del judaísmo en el siglo primero de la era de Cristo, y de las nuevas percepciones del proceso de separación de la iglesia-sinagoga.

Con nespecto a la naturaleza de los eruditos en judaísmo del primer siglo, como Jacob Neusner, Hayim Perelmuter y Efraim Shmueli, han enfatizado que el judarsmo del siglo primero estuvo lejos de ser monolítico." De hecho, esta fue una era muy creativa en la historia judia. Surgian nuevos grupos que retaban los puntos de vista del judaísmo tradicional. Lo que Ellis Rivkin ha llamado «the Pharisaic Revolution» (la revolución farisaica), que claramente puso la semilla de las perspectivas de Jesús y el cristianismo temprano, fue establecido retando las perspectivas judias en muchas áreas. Neusner y Shniueli prefieren hablar de cjudaísmosn en lugar de rigudaísmon. Desde que las interpretaciones cristianas de las perspectivas del pacto ánico están a menudo enraizadas a una comprensión posterior lineal del judaísmo, su queja acerca de los judaísmos como la figura auténtica de la creencia judía en el siglo primero propone un genuino reto para un modelo del pacto único que permanece basado en un conocimiento más uniforme y lineal de 
la tradición judia. Asimismo, debe decirse que una teoría del pacto único puede, a menudo, enmascarar un entendimiento continuo del cristianismo como una complementación del judaismo a lo largo de las líneas cristianas clásicas. Semejantes teologías de complementación, aun si contienen un punto de vista positivo de la tradición bíblica judía y defienden una conservación del pacto judio después de Cristo, tienen dificultad en contestar la pregunta a la que el judaísmo estä cristianamente unido y que deberia completar. La mayoría de los defensores de la teoría del pacto único no han tratado realmente con esta nueva compleja figura de la tradición judia.

La otra dimensión de estudio reciente tiene que ver con cốmo y cuándo se realizó la separación de la iglesia y la sinagoga. La mayoría de los cristianos estuvo apartada en la idea de que la iglesia estaba básicamente establecida como una entidad religiosa distintiva en el tiempo que Jesús murió en el Calvario. Por cl lado judio, la posición prevaleciente era que mientras Jesús, obviamente, mantenia lazos con la comunidad judía, era Pablo, a través de su misión con los gentiles, quien realmente trajo una total separación entre el cristianismo y el judaísmo. Ambas perspectivas ahora parecen bastante simplicistas. Aun si manejamos como factores las decisiones supuestamente hechas en el lado cristiano durante el llamado Concilio de Jerusalén (del que se habla en el libro de los Hechos), y en el lado judio en el Sinodo de Jabneh (que supuestamente colocó a los cristianos fuera de los parámetros de la comunidad judia), sabemos ahora que ni el Concilio ni el Sinodo dieron un cierre final al resultado de si los cristianos son simples seguidores del camino de Jesús judío o una comunidad distintiva religiosa nueva cuyos puntos de vista han roto definitivamente cual quier lazo inicial con el judaísmo,

Eruditos cristianos y judíos ahora importantes sostienen que la actual separación entre la iglesia y la sinagoga, aunque bien avanzada por el 
año 100 de la era cristiana, no fue completada sino varios siglos después. Estos eruditos, como Robert Wilken, Wayne Meeks, Alan Segal y Anthony Saldarini, han develado continuos lazos entre ciertas comunidades judías y cristianas, particularmente en el Este. ${ }^{10} \mathrm{La}$ evidencia de dichos lazos es aparente en los siglos segundo, tercero y, en unos pocos lugares, incluso en el cuarto. Y los lazos no eran simplemente un nivel de identidad religiosa; también afectaron la práctica popular. John Chrysostom, por ejemplo, lanzó una aguda crítica al judaísmo debido, en parte, a la frustración causada por el hecho de que los cristianos en su área continuaban participando en los servicios de la sinagoga en forma tegular.

El rol que tenian estos asistentes cristianos a la sinagoga es desconocido, y es probable que permanezca asi, a menos que alguien descubra un nuevo escondite de documentos en una cueva. Obviamente, seria terriblemente aclaratorio tener dicha información.

Pero, resumiendo, podemos decir que en el lado cristiano la gente creia que su aceptación de Jesús no reducia la importancia de particípar en el ritual judio. En el lado judio, debía de haber ciertamente algún reconocimiento de que los cristianos upertenecíany auténticamente a la comunidad, ya que no existe evidencia de que tuvieran que luchat en su camino hacia la sinagoga para los servicios del Shabbat.

Como resultado de ese nuevo estudio, un número de aquellos que habian estado profundamente envueltos en reconsiderar la teología de la relación judio-cristiana a través de los años ha comenzado a sentir, en cierta medida, insatisfacción con las primeras imágenes en el diálogo. Los esfuerzos iniciales para representar la relación entre el judaismo y la cristiandad en un lenguaje de umadre-hija» o «hermana mayor-hermana menot», $\mathrm{O}$ aun en términos de pacto único-pacto doble, que ahora parecen inadecuados. De 
alli que un número de nuevos modelos de comprensión de la compleja relación han comenzado a surgit.

En medio de las imágenes nuevamente emergentes de la relación cristiana-judia, las siguientes aparecen para llevar la mayor promesa. La primera es la noción de «siblings» (hermanos biológicos) avanzada por los eruditos judíos Alan Seaga y el fallecido Hayim Perelmuter. Esta imagen afirma que dos comunidades nuevas resultaron de la revolución que se llevó a cabo en el judaísmo del Segundo Templo. La primera fue el judaismo rabínico; y la segunda, la iglesia cristiana. Ambas fueron más allá de las encarnaciones iniciales del judaísmo en su mensaje básico. Aunque ellas tenian algunas conexiones iniciales, luego se dividieron en comunidades religiosas distintas y separadas. Este modelo tiene la ventaja de acentuar continuos lazos (los «hermanos biológicos" permanecieron conectados sin importar cuán dístintos llegaban a ser), a la vez que permite reconocimiento de que el cristianismo es mucho más que un judaísmo para los gentiles.

Otra imagen a lo largo de las mismas lineas es resaltada por Mary Boys en su importante nuevo volumen Has God Only One Blessing? Ella representa a judíos y cristianos como ugemelos fraternales». Esta imagen tiene la misma ventaja que los «hermanos biológicos», aunque ella postula una conexión de alguna forma más profunda entre judios y cristianos que, inclusive, el modelo de los hermanos biológicos. Su modelo podría, de hecho, inclinar demasiado el lado conectado de la relación en lugar del desconectado. Creo que es necesario acentuar que el judaísmo y el cristianismo han llegado a ser, a través de los siglos, comunidades religiosas distintivas. Mientras que su vinculo necesita énfasis, y el cristianismo necesita recuperar sus raíces judías, el judaísmo y el cristianismo postbíblico se diferencian en formas significativas en sus aproximaciones al entendimiento religioso; y nosotros no deberiamos jactarnos sobre ello, 
El teólogo Clark Williamson, que ha escrito importantes obras acerca de la relación cristiano-judia, como A Guest in the House of Israel, ${ }^{\text {th }} \mathrm{y}$ ha sido un participante activo por muchos años en el continuo grupo de eruditos cristianos sobre los judíos y el judaísmo, defiende un modelo de relación básica de «compañeros en espera», una imagen mảs abierta: carece del énfasis en la unión inherente contenida en los modelos de whermanos biológicos» $y$ «gemelos fraternos». Los «compañeros», después de todo, no tienen lazos familiares, pero sí implica alguna conexión en términos de esperanza futura. Hay también un sentido de testigo común al mundo implícito en el modelo de Williamson.

El modelo final está en proceso de ser desarrollado por el erudito Daniel Boyarmn de la Universidad de California. En una serie de discursos en la Universidad de Chicago y en la Catholic Theological Union (Chicago), Boyarnn ha propuesto la tesis de que lo que finalmente resultó de la revolución compleja social religiosa en el judaísmo del Segundo Templo, fueron dos nuevas comunidades religiosas distintivas: judaísmo rabínico y cristianismo. De ese modo, para Boyarin, deberiamos imaginar la relación cristiano-judía en términos de «comunidades religiosas coemergentes». Su perspectiva se apoya bastante bien en la evidencia histórica que ahora tenemos a la mana en têrminos de la multiplicidad de los «judaismos» en el tiempo de Jesús y en el proceso gradual de separación que se ha señalado antes; pero es más débil que otras imágenes en acentuar la continua unión entre iglesia y sinagoga.

Todavía estamos en las primeras etapas de esta segunda reconsideración contemporánea de la relación cristiano-judía. Hay que notar que las imágenes nuevamente emergentes son todas más paralelas que lineales en su entendimiento de la relación, a diferencia de las imágenes del pacto único, madre-hija y hermano mayor-hermano menor. Sería la discusión de todos los eruditos 
involucrados en este pensamiento el hecho de que no es posible encontrar simples líneas rectas desde judaísmo bíblico al judaísmo y cristianismo rabínico. Seguramente, permanece una conexión, pero no tan lineal como se creyó alguna vez. Necesitamos, ahora, continuar el proceso de reflexión. Pueden aparecer nuevos modelos que capturarín la complejidad de la relación aun mejor que aquellos que nosotros hemos brevemente examinado. Por ahora, mi preferencia es por el modela «hermanos biológicos». Creo que toma en cuenta el trabajo iniciador de Daniel Boyarin, pero nos deja con un balance mejor y más claro en cuanto a similitud y distinción.

El nuevo entendimiento histórico de separación gradual de la iglesia y la sinagoga asocia el cambio de postura teológico con respecto a la relación judio-cristiana en el Vaticano II. Nostra Aetate y documentos protestantes paralelos como el del Sínodo de Rhineland de Alemania exigen, en la comunidad cristiana, la necesidad de una reconsideración profunda de cómo nosotros entendemos y representamos fundamentalmente la relación cristiano-judia. Esta es, a la vez, una preocupación para los judios. Por ello, estoy contento de que el documento judío Dabru Emety su libro acompañante Christianily in jewish terms ${ }^{17}$ hayan comenzado un proceso de reconsideración de la relación desde el lado judio. 


\section{Notas}

'Kittel, Gerhard y Gerhard Friedrick (eds). Theological Dictionary of the New Testament. Grand Rapids y Michigan: Eerdmans, 1977.

${ }^{3}$ Kittel, Gerhard. Die Judefrange. Stuttgart: Kohlhammer, 1973, p. 73.

${ }^{3}$ Noth, Martin. The Lays in the Pentatesch and Other Studies. Edinburgh: Oliver and Boyd, 1966

'Bultmann, Rudolf. Theology of the New Testament. Nueva York: Scribners, 1951.

${ }^{3}$ Gutiérrez, Gustavo, A theology of Liberation. Maryknoll y Nueva York: Orbis, 1973, p. 161.

'Williamson, Clark, «Christ against the Jews: a Rewiew of Jon Sobrino's Christology». En Rosseau, Richard (ed.). Christiantify and Juddism: the Deepening Dialogue. Scranton: Ridge Row Press, 1983, p. 148.

'Stendhal, Krister. «The Apostle Pail and the Instrospective Conscience of the Wests. Harvard Theological Review, n. ${ }^{\circ} 56,1963$,pp. 199-216.

${ }^{\text {"}}$ Perelmuter, Hayim y Wilhelm Wuellher (eds.) Procedings: Conference on the Questions of the Letters of Paul Vieved from the Penpective of the Jevish ResponseMode. Chicago: Catholic Theological Union, 1991. "Martini, Carlo. "Christianity and Judaism: a Historical and Theological Owerviews, En Chatlesworth, James (ed.). Jeus and Cbristians: exploring the Past, Present and Futura. Nueva York: Crossroad, 1990, p. 19.

${ }^{10}$ Croner, Helga (ed.). More Stepping Stones to Jenrish Christian Relations: an Unabridged Collection of Cbristian Documents 1975-1983. Nueva York y Mahwah: Paulist Press, 1985.

"Cfr. Bernardin, Joseph. A Blessing to Each Other: Cardinal Joseph Bernardin and the Jevish-Catholic Dialogue. Chicago: Liturgy Training Publications, 1996, pp. 78-79.

${ }^{12}$ Kasper, Walter «The Good Olive Treev. America, n. ${ }^{\circ} 185,17$ de septiembre de 2001, p. 7.

${ }^{13} \mathrm{Cfr}$. Neusner, Jacob. Death and Birth of Judaism: the Impact of Christianity, Secularisun and Holocanst on Jewish Faith. Nueva York: Basic Books, 1987; Abmueli, Efraim. Seven Jewish Cultures: a Reinterpretation of Jenish History and Thought. Cambridge y Nueva York: Cambridge University Press, 1990; y Goren Perelumeter, Hayim. Siblings: Rabbinic Judasm and Early Christianity at Their Beginnings. Nueva York: Paulist Press, 1989.

"Cfr, Meeks, Wayne y Robert Wilken. Jens and Christians in Ancioch in the Fint Four Cemlarios. Missoula: Scholars Press, 1978; Willken, Robert. John Cbrysastom and the Jowst Rhetoric and 
Reality in the Late Century. Berkeley: University of California Press, 1983; Saldarini, Anthony. wews and Christians in the Frst Two Centuries: the Changing Paradigms. Shofar, n." 10 , 1992; $y$ Scroggs, Robin. «The Judaizing of the New Testamentw. The Chicago Theologital Seminary Register, n. ${ }^{7} 75,1986$, p. 1.

"Boys, Mary, Has God only One Blessing? Judaism as a Soune of Cbristian Self sunderstanding. Nueva Yorky Mahwah: Paulist Press, 2000.

"Williamson, Clark. A Guest in the House of Lrael- Post-bolocaust Christian Tbeology. Louisvilley Westminster: Jhon Knox, 1993.

${ }^{17}$ Cfr. Frymer-Kensky, Tikva David Novak ef al (eds.). Christian in Jevish terms. Boulder: Westview, 2000; Pawlikowski, John. "Christianity in Jewish Terms: revisioning Our Selfunderstanding . The Living Light, vol. $38, \mathrm{n} .{ }^{\circ} 1$, otoño de 2001, pp. $66-72$. 